\title{
Adverse obstetrical and perinatal outcome in adolescent mothers associated with first birth: a hospital-based case-control study in a tertiary care hospital in North-East India
}

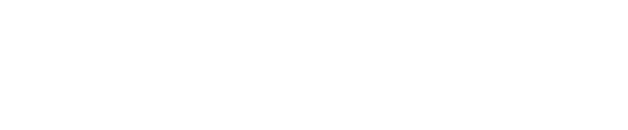

\section{Robin Medhi \\ Banani Das \\ Arpana Das \\ Mansur Ahmed \\ Sonika Bawri \\ Suditi Rai}

Department of Obstetrics and Gynaecology, Silchar Medical College and Hospital, Silchar, Assam, India
Correspondence: Banani Das Silchar Medical College, Ghungoor, Silchar 788014,Assam, India

Tel +9l 9864026537

Email drbananiz85@gmail.com
Purpose: To analyze the adverse obstetrical and perinatal outcome of adolescent mothers associated with first birth

Patients and methods: This prospective case-control study was conducted in a tertiary care teaching hospital of North-East India between January 2014 and December 2014. All adolescent primigravidae completing 28 weeks of gestation with singleton pregnancy and delivered at our institution were included in the study group. Primigravidae aged between 20 and 25 years were taken as a control group. Mothers having pregnancy complicated with diabetes mellitus, renal disorder, thyroid disorders, and cardiac diseases were excluded from the study. Demographic data, maternal complications like severe anemia, pre-eclampsia, eclampsia, gestational age at delivery, mode of delivery, and postpartum complications were compared. Among fetal complications, low-birth weight, preterm birth, neonatal intensive care unit admission, still birth, and early neonatal death were compared. All the patients were interviewed regarding contraceptive knowledge and its use preceding the pregnancy.

Results: Quality antenatal care was received by $80.6 \%$ of adolescent mothers. The adolescent mothers had a higher incidence of pre-eclampsia (odds ratio [OR] $2.01795 \%$ confidence interval $[\mathrm{CI}]:$ 1.045-3.894, $P=0.03$ ), preterm deliveries (OR: 1.655, 95\% CI: $1.039-2.636, P=0.03$ ). Among fetal outcomes, the low- birth weight babies (OR: 1.59, 95\% CI: 1.016-2.478), low mean birth weight $(2,544.4 \pm 622.09 \mathrm{~g}$ versus $2,701.6 \pm 582.51 \mathrm{~g})$, and higher admission to neonatal intensive care unit (OR: 1.957, 95\% CI: 1.120-3.417) were significantly associated with adolescent mothers. There was no significant difference found regarding the mode of delivery, still birth, and early neonatal death. Moreover, contraceptive knowledge and its use were found to be poor among adolescent mothers.

Conclusion: With quality antenatal, intranatal, and postnatal care, the obstetric risk of childbirth in adolescent mothers may not be as serious as perceived to be.

Keywords: teenage, primigravidae, childbirth outcome, contraceptive

\section{Introduction}

Adolescent pregnancy is considered as high-risk pregnancy and has enormous negative socioeconomic impact at the individual level as well as on the society. According to World Health Organization (WHO), adolescent pregnancy means pregnancy between 10 and 19 years of age. However, statistics comparing the incidence between countries often gives rates per 1,000 adolescent aged 15-19 years. ${ }^{1}$ According to WHO, 16 million adolescent mothers give birth annually and nine of every ten adolescent birth belong 
to low- and middle-income countries. ${ }^{2}$ The adolescent birth rate is lowest in Japan and Denmark whereas higher rates are found in Nigeria and Republic of Congo. According to World Bank data of 2013, there were 32 adolescent births for every 1,000 girls aged 15-19 in India. ${ }^{3}$ Deeply entrenched practice of child marriage, poor access to health care, poverty, and low literacy are mainly responsible for the high rate of adolescent pregnancy in India.

Controversial views exist regarding the obstetric performances of adolescent women. Some studies could not find any adverse pregnancy outcome among adolescent mothers with provision of high-quality maternity care. ${ }^{4,5} \mathrm{~A}$ recent study in Finland, where high-quality care is available to all pregnant mother, reported higher risk of anemia, urinary tract infection, pyelonephritis, eclampsia, preterm delivery, and adverse neonatal outcome among adolescent mother with inadequate antenatal care. The study also reported that there is a higher risk of pre-eclampsia among adolescent girls of 13-15 years of age. ${ }^{6}$ While in some other studies, mostly from developing countries, pre-eclampsia, eclampsia, anemia, premature labor, operative delivery, postpartum hemorrhage (PPH), low-birth weight, still birth, and neonatal death were found to be associated with adolescent pregnancy. ${ }^{7-10}$ In a large multicountry study done by WHO in low- and middle-income countries reported that eclampsia, puerperal infection, preterm birth, low-birth weight, still birth, and early neonatal death were significantly higher among adolescent mothers. ${ }^{10,11}$

It remains a matter of debate as to how much of these obstetrical and perinatal complications are attributable to age as opposed to availability, utilization and quality of health services, educational level, marital status, race, and other socio-demographic factors. Moreover, this difference in adverse outcome may be due to the use of different methodologies by different authors. Adolescent mothers face significant socioeconomic challenges and the public cost of adolescent childbearing is enormous. According to a United Nations report in 2013, the productivity of India would be $\$ 7.7$ billion higher if adolescent pregnancy could be prevented. ${ }^{12}$

In a major shift of health policy, Government of India launched a flag shift health program National Rural Health Mission (NRHM) in 2005 renamed as National Health Mission (NHM) in 2015, with the aim to reduce maternal mortality rate and infant mortality rate by providing completely free health care service to all pregnant women and children up to 1 year of age along with improvement in health care delivery system. The program also provides monetary incentives to the mothers as well as the accompanying field level trained health workers for hospital delivery. As a positive impact of the program, maternal mortality rate has reduced from 254 in 2005 to 178 in 2013, infant mortality rate has reduced from 58 in 2005 to 40 in 2013, and the rate of hospital delivery has significantly increased.

Our objective of the study was to find out the obstetric complications during antepartum, intrapartum, and postpartum period and the perinatal outcome of adolescent primigravidae in India with the changing health scenario.

\section{Patients and methods}

This prospective case-control study was conducted from January 2014 to December 2014, in a tertiary teaching hospital in North-East India where more than 10,000 deliveries occur annually. All adolescent primigravidae completing 28 weeks of gestation with singleton pregnancy booked and delivered in our institution as well as referred cases for delivery were included in the study group. Age is taken as the age at delivery. Adult primigravidae of 20 to 25 years of age who delivered next to adolescent mother were taken as a control group. Age between 20 and 25 years were taken as control as this age group is regarded as low risk for childbirth. For each adolescent primigravidae two adult mothers were taken in the control group. Excluded from the study were mothers having multifetal gestation, pregnancy complicated with diabetes mellitus, renal disorder, thyroid disorders, and cardiac diseases. The data were collected by using a structured and pre-tested proforma. Demographic data, pregnancy complications like severe anemia, pre-eclampsia, eclampsia, gestational age at delivery (gestational age is calculated from last menstrual period and second trimester sonography), mode of delivery, postpartum complications were compared. Among fetal complications low-birth weight, preterm, Apgar score at 1 and 5 minutes, neonatal intensive care unit (NICU) admission, still birth, and early neonatal death were recorded. All the patients along with their husband were interviewed about their knowledge and use of contraception preceding the pregnancy.

Severe anemia was defined as hemoglobin level $\leq 7 \mathrm{~g} / \mathrm{dL}$. Pre-eclampsia was defined as diastolic blood pressure $\geq 90 \mathrm{~mm}$ of $\mathrm{Hg}$ and/or systolic blood pressure $\geq 140 \mathrm{~mm}$ of $\mathrm{Hg}$ recorded on two occasions, 4 hours apart with $\geq+1$ dipstick proteinuria, after 20 weeks of gestation in a previously normotensive and non-proteinuric women. Birth weight $<2.5 \mathrm{~kg}$ was taken as low-birth weight babies. Delivery before 37 completed weeks was defined as preterm. Early neonatal death was taken as death within 7 days of life.

The study protocol was approved by the Institutional Review Board of Silchar Medical College and Hospital. 
Written informed consent was obtained from all study participants. The data were compiled and analyzed using the SPSS 15. For comparison, chi-square test and unpaired $t$-test were used for qualitative and quantitative data, respectively. Odds ratio (OR) and $95 \%$ confidence interval (CI) were used to identify the strength of association. The association was considered significant at $P$-value $<0.05$.

\section{Results}

During the study period, there were 10,123 deliveries, of which 165 adolescent primigravidae fulfilling the inclusion criteria included in the study group and 330 adult primigravidae were taken as control group, respectively. The mean age in adolescent group was $17.72 \pm 1.12$ years. There was no adolescent mother aged less than 15 years. The mean age in adult mothers was $22.54 \pm 2.35$ years. The different sociodemographic characteristics are given in Table 1.

In our study, all the mothers were married in both the groups. The mean duration between the marriage and the conception was $4.8 \pm 1.2$ months in adolescent group and $7.2 \pm 1.54$ months in adult group. The low level of education was significantly higher in adolescent group in comparison to control group. In our study, approximately $80.6 \%$ adolescent mothers received antenatal care. There was no significant difference of antenatal care between adolescent and older mothers.

Table 2 represents the obstetrical characteristics of adolescent mothers and those of adult women aged 20-25 years.

Table I Socio demographic characteristics of the study group and the control group

\begin{tabular}{|c|c|c|c|}
\hline \multirow[t]{3}{*}{ Variables } & \multicolumn{2}{|l|}{ Maternal age } & \multirow[t]{3}{*}{$P$-value } \\
\hline & $15-19$ years & $20-25$ years & \\
\hline & $\%(n=165)$ & $\%(n=330)$ & \\
\hline Maternal age, (mean \pm SD) & $17.72 \pm 1.12$ & $22.54 \pm 2.35$ & 0.0001 \\
\hline $\begin{array}{l}\text { Marital status } \\
\text { Married }\end{array}$ & $100(165)$ & $100(330)$ & \\
\hline $\begin{array}{l}\text { Antenatal care received } \\
\text { Educational status }\end{array}$ & $80.6(133)$ & $81.2(268)$ & 0.862 \\
\hline$<6$ years of schooling & $7.88(13)$ & $4.55(15)$ & 0.0001 \\
\hline $6-8$ years of schooling & $67.88(112)$ & $23.94(79)$ & \\
\hline $8-10$ years of schooling & $20(33)$ & 44.84 (I 48) & \\
\hline$>10$ years of schooling & $4.24(7)$ & $26.67(88)$ & \\
\hline $\begin{array}{l}\text { Time interval between } \\
\text { marriage and period } \\
\text { of conception (months) }\end{array}$ & $4.8 \pm 1.2$ & $7.2 \pm 1.54$ & 0.0001 \\
\hline \multicolumn{4}{|l|}{ Socio-economic status } \\
\hline Below poverty line & II.52 (19) & $7.88(26)$ & 0.02 \\
\hline Low class & $67.88(112)$ & 60.30 (199) & \\
\hline Middle class & $20.60(34)$ & $31.82(105)$ & \\
\hline
\end{tabular}

Note: Data shown as \% ( $n$ ) except for Maternal age and Time interval between marriage and period of conception (months) which are shown as mean \pm standard deviation.
The adolescent mothers had significantly higher incidence of pre-eclampsia in comparison to women aged 20-25 years. ( $P=0.03$, OR: $2.017,95 \%$ CI: $1.045-3.894)$. The mean gestational age at birth was significantly lower among adolescent mothers as compared to the adult mothers.

Incidences of severe anemia, eclampsia, antepartum hemorrhage, $\mathrm{PPH}$, and the mode of delivery were similar in both the groups.

Table 3 represents the perinatal complications of the adolescent mothers and those of women aged 20-25 years. The incidence of preterm delivery was significantly higher in adolescent group ( $P=0.03$, OR: $1.655,95 \%$ CI: $1.039-2.636$ ). The mean birth weight was significantly lower among the adolescent mothers with a $P$-value of 0.005 . The incidence of low-birth weight was also higher in adolescent age group $(P=0.042$, OR: $1.59,95 \%$ CI: $1.016-2.478)$ and also the NICU admission ( $P=0.02$, OR: $1.957,95 \%$ CI: $1.120-3.417)$. There was no statistical difference found in both the groups regarding low Apgar score, still birth, and early neonatal death.

Table 4 represents the contraceptive knowledge and its use. The contraceptive knowledge was present only in $13.94 \%$ of adolescent mothers as compared to adult mothers $(57.58 \%)$. The percentage of ever use of contraceptive methods in adolescent mothers was $4.24 \%$ as opposed to in older mothers. Both contraceptive knowledge and use were significantly lower in adolescent mothers.

\section{Discussion}

In developed countries, the rate of adolescent pregnancy has dropped over last 70 years. But in developing countries like India adolescent pregnancy is still rampant with enormous impact on maternal and child health. Thus, adolescent pregnancy becomes a public health problem in India and needs to be tackled on a priority basis.

In our study, all the pregnancy occurred within marriage, and the majority $(>80 \%)$ received quality antenatal care in our tertiary hospital in both groups. In our study, the percentage of adolescent mothers receiving antenatal care is higher than the previous reported literatures from India. ${ }^{13}$ This is due to effective implementation of NRHM (NHM) in this region. Approximately $80.6 \%$ of adolescent mothers had early booking and delivered in our institution and $19.4 \%$ of cases referred from the interior areas with sub-optimal antenatal care. Fewer adverse outcomes among adolescents in our study may be due to quality antenatal, intranatal, and postnatal care. The importance of quality maternity care in reducing the adverse outcomes of adolescent pregnancy is highlighted in few reports. ${ }^{4,5,14}$ 
Table 2 The obstetrical complications of the adolescent and adult mothers of 20-25 years

\begin{tabular}{|c|c|c|c|c|}
\hline \multirow[t]{3}{*}{ Variables } & \multicolumn{2}{|l|}{ Maternal age } & \multirow[t]{3}{*}{ Odds ratio $(95 \% \mathrm{Cl})$} & \multirow[t]{3}{*}{$P$-value } \\
\hline & $15-19$ years & $20-25$ years & & \\
\hline & $\%(n=165)$ & $\%(n=330)$ & & \\
\hline Pre-eclampsia & $11.52(19)$ & $6.06(20)$ & $2.017(1.045-3.894)$ & 0.03 \\
\hline Eclampsia & $3.03(5)$ & $2.12(7)$ & $0.995(0.310-3.193)$ & 0.54 \\
\hline Antepartum hemorrhage & $1.21(2)$ & $0.9(3)$ & $1.337(0.221-8.083)$ & 0.75 \\
\hline Severe anemia & $2.42(4)$ & $3.03(5)$ & $1.615(0.4278-6.096)$ & 0.48 \\
\hline Vaginal delivery & $71.52(118)$ & $70(23 I)$ & $1.076(0.712-1.625)$ & 0.73 \\
\hline Cesarean section & $24.85(4 I)$ & $25.75(85)$ & $0.953(0.619-1.466)$ & 0.83 \\
\hline Vaginal instrumental delivery & $3.63(6)$ & $4.25(14)$ & $0.852(0.32 I-2.259)$ & 0.75 \\
\hline Postpartum hemorrhage & $1.8(3)$ & $1.21(4)$ & $1.509(0.334-6.824)$ & 0.59 \\
\hline Gestational age at delivery & $38.12 \pm 2.47$ & $38.69 \pm 2.87$ & - & 0.03 \\
\hline
\end{tabular}

Notes: Data shown as \% ( $n$ ) except for Gestational age at delivery which are shown as mean \pm standard deviation. - represents no data.

Abbreviation: $\mathrm{Cl}$, confidence interval.

Low educational level and poor socioeconomic status were found to be significantly associated with adolescent mother in contrast to the adult group. In a society with low literacy rate, people are likely to follow the age-old social custom of marrying off a girl child at an early age. Poverty and sex biasness act as a catalyst for early marriage of girl child. In our study, the pre-eclampsia was found to be significantly associated with adolescent mothers. This finding corroborates with previous studies. ${ }^{7-9,15}$ However, no significant difference was found regarding eclampsia in contrary to their studies. The probable explanation is that most mothers received treatment at pre-eclamptic state.

Opinion regarding the mode of delivery in adolescent pregnancy differs widely. Various literatures cited that there is biological immaturity of the adolescent pelvis which causes cephalo-pelvic disproportion leading to an increase in cesarean section rate. ${ }^{9,15,16}$ Our study did not find any increase in the rate of cesarean section among adolescent mothers. This can be explained that adolescent mothers give birth to small size babies. Our finding with respect to the mode of delivery is contrary to the widely held belief that the adolescent mothers need cesarean delivery. A similar view expressed in some other studies. ${ }^{7,8,13,17}$

We found that adolescent pregnancy was associated with increased risk of preterm births which is consistent with various literatures. ${ }^{7,9,18}$ The mechanism of preterm labor among adolescent mothers is still unclear. However, one physiological reason is the immaturity of the uterine and cervical blood supply in young mothers which leads to increase in prostaglandin production leading to preterm labor. Another recent view is that, lack of proper menstrual preconditioning among young adolescent interfere with the process of decidualization and trophoblastic invasion that increases the risk of defective deep placentation that leads to preterm deliveries in adolescent primigravidae. This also partly explains the increased rate of pre-eclampsia among young adolescent mothers. ${ }^{19}$ Other contributing factors may include low socio-economic status, young maternal age at first delivery, and hypertensive disorders of pregnancy.

Table 3 Perinatal outcomes of the adolescent and adult group

\begin{tabular}{|c|c|c|c|c|}
\hline \multirow[t]{3}{*}{ Variables } & \multicolumn{2}{|l|}{ Maternal age } & \multirow[t]{3}{*}{ Odds ratio $(95 \% \mathrm{Cl})$} & \multirow[t]{3}{*}{$P$-value } \\
\hline & $15-19$ years & 20-25 years & & \\
\hline & $\%(n=165)$ & $\%(n=330)$ & & \\
\hline Preterm birth & 23.64 (39) & $15.76(52)$ & $1.655(1.039-2.636)$ & 0.03 \\
\hline Birth weight (mean $\pm S D$ ) & $2,544.4 \pm 622.09$ & $2,70 \mathrm{I} .6 \pm 582.5$ & & 0.005 \\
\hline Low birth weight & $26.06(43)$ & $18.18(60)$ & $1.59(1.016-2.478)$ & 0.042 \\
\hline Low Apgar score ( $<7$ in I minute) & $12.12(20)$ & $13.03(43)$ & $0.921(0.522-1.623)$ & 0.78 \\
\hline Low Apgar score ( $<7$ in 5 minutes) & $3.6(6)$ & $3.9(13)$ & $0.920(0.343-2.466)$ & 0.87 \\
\hline Neonatal intensive care unit & $16.36(27)$ & $9.09(30)$ & $1.957(1.120-3.417)$ & 0.02 \\
\hline \multicolumn{5}{|l|}{ (NICU) admission } \\
\hline Still birth & $3.03(5)$ & $2.42(8)$ & $1.258(0.405-3.907)$ & 0.69 \\
\hline Early neonatal death & $2.42(4)$ & $1.5(5)$ & I.442 (0.45I-4.6I5) & 0.48 \\
\hline
\end{tabular}

Abbreviations: $\mathrm{Cl}$, confidence interval; $\mathrm{NICU}$, neonatal intensive care unit; $\mathrm{SD}$, standard deviation. 
Table 4 Presence of contraceptive knowledge and use

\begin{tabular}{llll}
\hline & Study group & Control group & $\boldsymbol{P}$-value \\
\hline Contraceptive knowledge & $13.94(23)$ & $57.58(190)$ & 0.000 I \\
Ever use contraception & $4.24(7)$ & $38.79(128)$ & 0.000 I \\
\hline
\end{tabular}

The incidence of low-birth weight babies in adolescent mothers was significantly higher in comparison to the mothers of 20-25 years. Being preterm babies, there are also higher incidences of the NICU admission rate. This observation corroborates with various other literatures. ${ }^{7,9,18,20}$

In a multicountry study ${ }^{5}$ done by WHO in India, it was found that, the still birth and early neonatal death rate were significantly higher among adolescent mothers. While the perinatal outcome in our study does not corroborate with the WHO study probably because of the difference in the level of health care facilities included in their studies. Our study was done in a tertiary care hospital where advanced neonatological facilities are available.

The time period of interval between the marriage and the conception was found to be less among adolescent mothers in comparison to the adult group. It has been reported that there is increase fertility among the adolescent group. ${ }^{20}$ Another contributing factor was low and irregular use of contraceptive in adolescent age group.

In our study, the contraceptive knowledge and use were lower in adolescent group. The low level of contraceptive knowledge and its use is possibly because of the low level of education and low access to contraceptives in adolescent mothers in comparison to older mothers of 20-25 years of age.

The limitation of the study is that, since the study was conducted in a tertiary hospital where high-quality maternal and neonatal care facilities were available the findings may not truly reflect the situation of the whole population. Moreover, we could not include adolescent mother less than 15 years who are at risk of severe obstetrical and neonatal complications. In the study region, pregnancy in this age group is rare. Isolated cases of pregnancy do occur among younger adolescent, but mostly out of wedlock and likely to end up in legal/illegal abortion. Such young mother rarely comes to avail health care facility at a tertiary center because of the social stigma associated with it. We also did not evaluate the psychological impact of pregnancy among adolescent mothers.

\section{Conclusion}

Adolescent pregnancy may not be associated with serious obstetrical complications as perceived, if high-quality antenatal, intranatal, and postnatal care are provided. Higher level of education is an important deterrent to early marriage and early childbearing. It is strategically important to delay marriage and pregnancy in adolescent married girls in view of a population explosion that mid- and low-income countries are facing. In addition to quality health care services, a dedicated educational policy aimed at promoting education among girl child seems to be an effective measure to reduce the burden of adolescent pregnancy in the developing world.

\section{Disclosure}

The authors report no conflicts of interest in this work.

\section{References}

1. World Health Organization. Adolescent Pregnancy: Issues in Adolescent Health and Development. Geneva: World Health Organization; 2004. (WHO discussion papers on adolescence).

2. World Health Organization. Early marriages, adolescent and young pregnancies 2011. Geneva: World Health Organization. Available from: http://apps.who.int/gb/ebwha/pdf_files/EB130/B130_12-en.pdf. Accessed November 19, 2015.

3. The World Bank. Adolescent Fertility Rate (births per 1000 women aged 15-19 years). United Nations Population Prospects. Available from: http://data.worldbank.org/indicator/SP.ADO.TFRT. Accessed November 19, 2015.

4. Raatikainen K, Heiskanen N, Verkasalo PK, Heinonen S. Good outcome of teenage pregnancies in high-quality maternity care. Eur J Public Health. 2006;16:157-161.

5. Blomberg M, Birch Tyberg R, Kjolede P. Impact of maternal age on obstetric and neonatal outcome with emphasis on primiparous adolescents and older women: a Swedish Medical Birth Register study. BMJ Open. 2014:4:e05840.doi:10.1136/bmjopen-2014-005840.

6. Leppälahti S, Gissler M, Mentula M, Heikinheimo O, Is teenage pregnancy an obstetric risk in a welfare society? a population-based study in Finland, from 2006 to 2011. BMJ Open. 2013;3(8): e003225.

7. Briggs MM, Hopman WM, Jamieson MA. Comparing pregnancy in adolescents and adults; obstetrics outcomes and prevalence of anemia. J Obstet Gynaecol Can. 2005;29(7):546-555.

8. Kumar A, Singh T, Basu S, Pandey S, Bhargava V. Outcome of teenage pregnancy. Indian J Paediatr. 2007;74(10):927-931.

9. Tufail A, Hasmi HA. Maternal and perinatal outcomes in teenage pregnancy in a community based hospital. Pak J Surg. 2008;24(2): $130-134$.

10. Ganchimeg T, Mori R, Ota E, et al. Maternal and perinatal outcomes among nulliparous adolescents in low - and middle - income countries: a multi country study. BJOG. 2013;120:1622-1630.

11. Ganchimeg T, Ota E, Morisaki N, et al. Pregnancy and childbirth outcomes among adolescent mothers: a World Health Organization multicountry study. BJOG. 2014;121:Suppl 1:40-48.

12. UNFPA. State of World Population 2013. Motherhood in Childhood. Facing the Challenge of Adolescent Pregnancy; 2013. Available from: http://www.unfpa.org/sites/default/files/pub-pdf/EN-SWOP2013-final. pdf. Accessed November 19, 2015.

13. Ago BU, Abeshi S, Njoku C, Agban TU, Ekabua J. Obstetric outcomes of booked teenage pregnancies at University of Calabar Teaching Hospital, Nigeria. Adolesc Health Med Ther. 2012;3:105-109.

14. Sulaiman S, Othman S, Razali N, Hassan J. Obstetric and perinatal outcome in teenage pregnancies. S Afr J OG. 2013;19(3):77-80.

15. WHO. Expert Committee Report. Physical Status: The Use and Interpretation of Anthropometry. Technical report Series 854, Geneva: World Health Organisation; 1995. 
16. Lao TT, Ho LF. Obstetrics outcomes of teenage pregnancy. Hum Reprod. 1998;13(11):3228-3232.

17. Iqbal F, Azad S, Tayyab R. Obstetrical and fetal outcome in teen age primigravida. Ann King Edward Med Coll. 2004;10(4):470-472.

18. Hidalgo LA, Chedraui PA, Chavez MJ. Obstetrical and neonatal outcome in young adolescents of low socio-economic status: a case control study. Arch Gynecol Obstet. 2005;271:207-211.
19. Mukhopadhyay P, Chaudhuri RN, Paul B. Hospital-based perinatal outcomes and complications in teenage pregnancy in India. $J$ Health Popul Nutr. 2010;28(5):495-500.

20. Brosens I, Benagiano G. Menstrual preconditioning for the prevention of major obstetrical syndromes in polycystic ovary syndrome. Am J Obstet Gynecol. 2015;213(4):488-493.

\section{Publish your work in this journal}

Adolescent Health, Medicine and Therapeutics is an international, peer-reviewed, open access journal focusing on health, pathology, and treatment issues specific to the adolescent age group. All aspects of health maintenance, preventative measures and disease treatment interventions are addressed within the journal and practitioners from all disciplines are invited to submit their work as well as healthcare researchers and patient support groups.. The manuscript management system is completely online and includes a very quick and fair peerreview system. Visit http://www.dovepress.com/testimonials.php to read real quotes from published authors.

Submit your manuscript here: http://www.dovepress.com/adolescent-health-medicine-and-therapeutics-journal 